\title{
Analisis Wacana Pesan Dakwah pada Film Cinta dalam Ukhwah
}

\author{
Yasyifa Fajaria Nursyamsi*, Dindin Sholahudin, dan Tata Sukayat \\ Jurusan Komunikasi dan Penyiaran Islam, Fakultas Dakwah dan Komunikasi, \\ UIN Sunan Gunung Djati, Bandung \\ *Email :yasifafajaria@gmail.com
}

\begin{abstract}
ABSTRAK
Penelitian ini memaparkan pesan dakwah dari kejelasan wacananya. Penelitian kualitatif ini menggunakan teori analisis wacana menurut Teun Van Djik dengan konsep 'kognisi sosial' istilah yang disadur dari pendekatan psikologi sosial untuk menjelaskan struktur dan proses terbentuk suatu teks. Hasil penelitian di film Cinta dalam Ukhuwah ini didapatkan tiga kesimpulan utama: pertama secara teks film ini mengandung Pesan dakwah dengan topik toleransi, ukhuwah dan inklusivisme. Kedua, kognisi sosial pengalaman pribadi penulis mempengaruhi bagaimana teks skenario diproduksi. Ketiga, konteks sosial permasalahan masyarakat Islam diangkat sebagai 'konflik dan anti klimaks' dalam dialog pada teks skenario dan film yang diproduksi. Cerita yang disampaikan dalam film di angkat dari wacana melalui pendekatan psikososial, mengkontruksi wacana tentang sikap kritis dan tabayun terhadap strategi yahudi ini sebagai pesan moral.
\end{abstract}

Kata Kunci : film; pesan; analisis wacana; dakwah.

\section{ABSTRACT}

This research describes the message of dakwah clarity of discourse. Film as a medium of da'wah becomes a thing to be examined both in terms of meaning and production, especially in the field of I'lam. Its presence in the scholarship of da'wah can be a reference that supports the spread of Islamic values. This qualitative research uses the theory of discourse analysis according to Teun Van Djik with the concept of 'social cognition' which is adapted from the social psychology approach to explain the structure and process of forming a text. The results of the film Love in this ukhuwah got three main conclusions: first the text of this film contain Message da'wah with the topic of 
tolerance, ukhuwah and inclusivism. Second, the social cognition of the author's personal experience affects how text scenarios are produced. Thirdly, the social context of Islamic societal issues is raised as 'conflict and anti-climax' in dialogue on scenarios and film texts produced. The story presented in the film is lifted from the discourse through psychosocial approaches, constructing discourses about critical attitudes and tabayun against this Jewish strategy as a moral message.

Keywords: movies; message; discourse analysis; da'wah

\section{PENDAHULUAN}

Abad ke 21 ini tabligh atau dakwah tidak hanya disampaikan diatas mimbar. Kemajuan teknologi dan perkembangan masyarakat yang heterogen maupun homogen segala hal yang bisa di jadikan alat atau perantara bertabligh maka itu disebut media. Berdasarkan sifatnya media tabligh memiliki kemampuan rangkaian tersendiri yang satu sama lain berbeda tapi satu tujuan, diantara: media bersifat auditif, media bersifat visual dan media bersifat audio visual. Dari ketiga jenis media tersebut maka media audio visual adalah hal yang paling menarik selain bisa melihat tayangan dengan mata audience pun bisa mendengarkan apa yang jadi tujuan pesan itu, dari banyak prodak audiovisual maka yang paling bnyak menyentuh dan memberikan efek adalah film.

Jurnal yang di tulis di buku Komunikasi Penyiaran Islam menyebutkan (Enjang, 2004:93) Film memberikan pengaruh yang besar pada jiwa manusia. Dalam suatu proses menonton film, terjadi suatu gejala yang disebut oleh ilmu jiwa sosial sebagai identifikasi psikologis. Ketika prosesi decoding terjadi, para penonton kerap menyamakan atau meniru seluruh pribadinya dengan seorang aktor dalam peran film.

Tinjauan penelitian sebelumnnya untuk mepertajam objektivitas dan orisinalitas penelitian penulis menampilkan beberapa penelitian sejenis yang relevan dengan penelitian sebagai berikut: pertama, skripsi karya Anggun Pramudya (2011) yang berjudul "Analisis wacana Film Alngkah Lucunya Negri ini Karya Deddy Mizwar" penelitian yang mengacu pada teori Harold Laswel dengan menggunakan metode content analysis. Kedua , Zakka Abdul Malik Mahasiswi UIN Syarif hidayatulloh tahun 2010 dengan karya "Analisis wacana dalam Film Titian Serambut di Belah Tujuh Karya Chairul Ummam” melalui pendekatan analisis deskripti dengan teori Ten A, Van Djik dalam kesimpulannya menyebutkan mengenai objek kajian wacana menurut sosisokultural dalam film tersebut. 
Pesan dakwah pada umunya berisi ajaran Islam itu sendiri. Secara umum dapat di kelompokkan menjadi pertama, pesan akidah, yang meliputi iman kepada Allah SWT, iman kepada Malaikat-Nya, iman kepada kepada kitab-kitabNya,iman kepada RasulNya, iman kepada hari akhir, iman kepada Qadha dan Qadhar. Kedua, pesan syariah yang pada garis besarya berbicara tentang ibadah. Sedangkan Akhlaq meliputi akhlaq manusia terhadap Allah SW'T, ahklaq terhadap makhluk yang meliputi akhlaqterhadap manusia, diri sendiri, tetangga, masyarakat lainnya, akhlaq terhadap bukan mnausia meliputi flora dan fauna dsb (Wahyu Ilahi:20)

Film bisa dijadikan alternatif dakwah yang diakui keefektifannya karena televisi dan perkembangan teknologi yang semakin pesat sehingga film bisa mejadi senjata yang baik dalam dakwah. Banyak orang Islam yang sulit untuk belajar membaca sejarah tapi film bisa memberikan pacaging yang menarik dan membekas.

Semakin hari dunia perfilman merombak habis bagaimna pesan dakwah bisa di terima dengan baik. Menerima komentar sumbang untuk menghasilkan film yang benar-benar bergengre dakwah.

Sebuah pesan akan terus tersurat jika tidak di teliti dengn pisau analisis yang tepat. Membaca makna dalam kotek sosial menjadi tugas analisis wacana dalam mengkaji teks, kognisi dan kondisi. (shobur 2010:68) Penelitian menggunakan penelitian analisis wacana (Discourse analysis) yaitu studi tentang struktur pesan atau telah mengenai aneka fungsi bahasa (pragmatik). Metode analisis wacana dalam model Teun A. Van Dijk mengutamakan tiga hal atau dimensi yaitu teks sosial, kognisi sosial, dan konteks sosial, dan inti dari model ini adalah menggabungkan ketiga dimensi tadi menjadi sebuah kesatuan (Unity).

Kerangka konseptual adalah paradigma penelitian kontruktivisme sebab jenis data yang di olah berdasarkan hasil analisis wacana berdasarkan kulitatif. Konten dan wacana di jadikan objek utama yang di analisi yang sifatnya dinamis memebuat konsep konstruktivisme menjadihal yang justru penting sebagai bahan evalusi dan solusi dari sebuah permasalahan.

Pendekatan yang di gunakan dalam penelitian kualitatif adalah pendekatan subjektif (fenomenologi). Sedangkan Metode yang di gunakan oleh peneliti adalah Analisis Wacana model Teun Van A Djik, menurutnya penelitian wacana tidak hanya pada teks semata, tetapi juga bagaimana suatu teks diproduksi. Inti analisis Van Djik menggabungkan tiga dimensi wacana ke dalam satu kesatuan analisis. Dalam hal ini, 
wacana film Cinta dalam Ukhwah meliputi konteks sosial, kognisi sosial dan teks skenario. Menganalisis superstruktur yang mencakup skematik yang ada dalam film tersebut. Terakhir adalah struktur mikro yang meliputi semantik, sintaksis, stalistik, retoris yang terdapat pada Film Cinta dalam Ukhwah. Dalam melaksanakan analisis ini, perlu dilakukan penyajian data yang merupakan sekumpulan informasi tersusun yang memberi kemungkinan adanya penarikan kesimpulan dan pengambilan tindakan.

Adapun subjek penelitian ini adalah film "Cinta dalam Ukwuah" yang pemikiran utamanya adalah M. Ali Gifar sebagai penulis skenario, anak-anak Lembaga Dakwah kampus yang belajar memaknai bagaimana tolerasi itu dekat dalam sebuah ukhwah. Sedangkan objek penelitiannya hanya fokus pada wacana kritis yang terdapat pada film cinta dalam ukhwah wacana kritis yang di maksud adalah menggambarkan amar ma'ruf, nahi munkar serta penanaman sikap terhadap individu yang terdapat di aplikasikan dalam kehidupan sehari-hari oleh masyarakat. Sumber data dari penelitian ini adalah berdasarkan naskah skenario dan film Cinta dalam ukhwah dan beberapa data pelengkap juga dari bukubuku pustaka yang penulis jadikan sumber bacaan.

Dalam menganalisis data ada beberapa jalan yang di tempuh adapun tahapan data yang di tempuh dengan cara: reduksi data, penyajian atau display dan penarikan kesimpulan atau verifikasi. Pada awalnya penulis telah melakukan penelitian dengan riset awal dengan bergabung dengan komunitas Film Maker Muslim Bandung Mensistematiskan pesan dengan cara mengkaji sruktur teks dan pembagiannya makro dan mikro dari teks skenario.Melakukan wawancara untuk mencari data seputar aspek kognisi sosial dan kritik sosial kepada penulis skenario dan sutradara film. Menganalisis respon dalam ulasan komen di youtube dalam kolom komentara pada tayangan Cinta dalam ukhuah. Menganalisis data-data sumber pendukung penelitian seperti naskah skenario dan film. Mengklasifikasikan pesan dakwah dari pencarian data seputar aspek kognisi sosial dan konteks sosial dengan lewat analisis yang digunakan. Menyimpulkan dengan cara menyimpulkan kembali hasil dari penafsiran data.

\section{LANDASAN TEORITIS}


Dakwah adalah komunikasi yang khas yang membedakan antara komuniasi secara umum adalah partisipasi dari komunikasi atas ide-ide atau pesan yang disampaikan sehingga dengan pesan-pean tersebut terjadi perubahan sikap dan tingkah laku yang diharapkan. Dalam dakwah demikian juga, seseorang da'i dalam komunikator, yang diharapkan partisipasinya, dalam mempengaruhi umat/komunikator, yang diharapkan partisipasinya dalam memengaruhi umat/komunikan dapat bersikap dan berbuat sesuai dengan isi pesan yang di sampaikan oleh da'i/komunikator (Saputra. 2011:231).

Artinya bisa di gabungkan secacra konseptual mengenai pengertian film dakwah, secara konseptual memiliki tujuan yang sama yakni membuat orang berubah ketika pesan/informasi diterima oleh penonoton/mad'u. Sehingga dika di tarik definsi film dakwah adalah film yang di buat degan tujuan menyampaikan informasi yang mengandung pesan atau nilai-nilai KeIslaman yang ketika selesai menonton film tersebut oarang di harapkan untuk bisa beramar makruf nahyi mungkar.

Di awal millenium baru ini tampakanya mulai ada gairah baru dalam industri perfilman Indonesia terutama dalam industri yang mengususng tema dakwah. Seperti film sudah dekat, Kun Fayakun, perempuan berkalung sorban, Ketika cinta bertasbih. perkembangan teknologoi membawa perubahan besar terhadap peradaban manusia. Dengan semakin maju teknologi infromasi menbuat bumi menjadi sempit. Film merupakan media komunikasi yang paling efektif untu menyebarkan nikai-nikai kepada msyarakata tentang perilaku dengan itu ada pelabelan yang lebih positif yang bisa di tiru. Melihat demikian film efektif sekalii di gunakan sebagai media penyampai syiar Islam kepada masyarakat luas.

Dalam konteks ilmu komunikasi, terdapat 12 prisip-prinsip komunikasi, salah satu diantaranya adalah; prinsip komunikasi dimensi isi dan dimensi hubungan. Maksudnya adalah bahwa dimensi isi disandi secara verbal, sementara dimensi hubungan disandi secara nonverbal.

Dalam penjelasan yang lain, dimensi isi menunjukan muatan (isi) komunikasi, yaitu apa yang diktakan/disampaikan. Dimensi hubungan apa menunjukan bagaimana cara mengatakan dan menyampaikan yang juga mengisyaratkan bagimana hubungan para peserta konunikasi itu, dan bagaimana pesan itu seharusnya di tafsirkan. Film sebagai salah satu media komunikasi tentunya memliki pesan yang akan di sampaikan. Maka isi pesan dalam film merupakan merupakan dimesi isi, sedangkan film sebagai alat (media) berposisi sebagai dimensi hubungan . dalam hal ini 
pengaruh suatu pesan akan berbeda bila di sajikan oleh media audio-visual (film dan televisi) boleh jadi menimbulkan pengaruh yang lebih hebat, misalnya dalam bentuk peniruan oleh anak-anak di bawah umur, oelh akren aitu Marshall Mckuhan mengatakan The Medium is Message (Asmara, 1997: 47)

Sedangkan film bisa di jadikan media/perantara dakwah karena memiliki tujuan yang sama yakni mengadung pesan yang ingin di sampaikan kepada khalayak ramai. Maka bisa ditarik kesimpulan Prinsip Film dakwah adalah film yang konsisten dalam pesannya mengandung nilai-nilai ke-Islamman. Atau dalam pengertian lain prinsip film dakwah adalah film yang di dalam ynya terdapat satu atau seluruh unsur-unsur dakwah.

Dalam sebuah artikel yang ditulis oleh Puput Tripeni Juniman, seorang jurnalis CNN Indonesia yang dimuat dilaman CCN Indonesia pada Kamis, 08/06/2017 12:55. Disebutkan bahwa tidak ada film yang bergenre religi hanya ada film bernuansa agama, Sutradara Hanung Bramantyo menilai anggapan itu merupakan salah kaprah yang terjadi di masyarakat. Hanung menyatakan kategori atau genre film religi itu bahkan tidak ada. "Kalau film religi itu tidak ada, yang ada itu film drama yang berlatar agama, karena dasar ceritanya adalah agama," kata Hanung kepada CNNIndonesia.com beberapa waktu lalu.

Dari sekelumit uraian diatas apanila di tarik kesimpulan bahwa film dakwah/ dakwah memalui film tidak harus melulu menonjolkan atribut ataupun simbol-simbol keIslamana secara wujud. Namun bisa juga disampaikan melakui kebenaran universal sebab ia lebih berdampak langsung pada kesadaran orang yang menontonnya hingga penontot mamapu menga,bil hikmah dari film tersebut.

Kata discourse berasal dari kata bahasa Latin yang berarti lari kiankemari (yang diturunkan dari di-'dari, dalam arah yang berbeda' dan curve'lar’) (Sobur, 2002:7). Ismail Marahimin mengartikan wacana sebagai "kemajuan untuk maju (dalam pembahasan) menurut urut-urutan yang harus dan semestinya", dan komunkasi buah pikiran, baik lisan maupun tulisan, yang teratur (Maharimin, 1994:26). Jika definisi ini di pakai sebagai pegangan maka dengan sendirinya semua tulisan yang teratur, yang menurut urut-urutan yang semestinya atau logis adalah wacana. Model yang dipakai oleh Van Djik kerap di sebut sebagian "kognisi sosial". Istilah sebenarnya diadopsi dari pendekatan lapangan psikologi 
sosial terutama untuk mejelaskan struktur dan proses terbentuknya suatu teks. Nama pendekatan semacam ini tidak dapat dilepaskan dari karakteristik yang di perkenalkan oleh Van Djik. Menurut Van Djik, penelitian atas wacana tidak cukup hanya didasarkan pada analisis teks semata, karena teks adalah hasil dari suatu praktek produksi yang harus diamati (Eriyanto, 2001: 221)

Maka, Vandjik menyempurnkannya dengan memfokuskan hasil dari ketgta penelitian yang di gabungkan. Pertama, Analisis wacana berdasarkan Teks: Struktur makro merupakan makna global /umum dari suatu teks yang dapat dipahami dengan melihat topik dari suatu teks. Superstruktur adalah kerangka suatu teks: bagaimana struktur dan elemen wacana itu di susun dalam teks secara utuh. Stuktur mikro adalah makna wacana yang dapat diamati dengan menganalisis kata, kalimat, proposisi, anak kalimat, parafprase yang di pakai dan sebagainya. Kedua analisis wacana dari dimensi kognisi sosial adalah titik kunci dalam memahami sebuah produksi tekas atau cerita, maksudnya adalah meniliti juga proses terbentuknya teks, prses terbentuknya teks ini tidak hanya bermakna bagiamana suatu teks itu di bentuk, tetapi juga proses ini mamasukan informasi yang di gunakan untuk menulis dari suatu bentuk wacana terntentu analisis kognisi sosial memusatkan perhatian pada struktur mental, proses pemaknaan, dan mentak komunikatir dalam memahami senuah fenomena dari proses produksi sebuat teks(Erianto, 266).

Ketiga, dari Vandijk kali ini adalah karakter sosisal yang terdapat dalam sebuah tekas adalah bagian dari wacana yang berkembang dalam masyarakat, sehingga untuk meneliti suatu teks perlu di lakukan analisis intertekstual dengan meneliti bagaimana wacana tentang suatu hal diproduksi dan di kontruksi dalam masyarakat.(Erianto, 2001: 271)

Film pertama FMM di fase ke 3 dengan durasi kurang lebih 45 menit ini menceritakan tentang kisah persahabatan, cinta, pedebatan dan selingan komedi. Berlatar belakang dan anggota UKM LDK kampus mejadi hal yang begitu relevan. Fim ini menceritakan persahabatan tiga orang lelaki sejak jaman di pesantren yang selalau berbeda pendapat karena fiqh mereka berbeda. Entah kenapa persahabatan atara Rio dan Azzam tibatiba merenggang tak seperti biasanya. Diceritakan juga sosok Najwa yang menambah cerita makin berkonflik anggota LDK kampus yang satu ini tidak berhijab, keadaannya yang tidak berhijab itu membuat anggota yang lain masih sulit untuk menerima baik kehadirannya. Dalam adegannya di perlihatkan para akhwat yang terkesan menghindari Najwa yang belum 
berhijab. Hingga suatu ketika muncul konflik dimana sikap Kikin yang keterlaluan menjugde Najwa. Film yang dipremierkan secara ekslusif selama setahun di berbagai kota di Indonesia baru tayang di youtube setelah bulan ke sepuluh. Secara emosional film ini cukup meguras emosi bagimana konflik bermunculan dan terus berkembang, film ini memberikan pelajaran bahwa janganlah memandang diri kita lebih baik dari orang lain. Selain itu film ini memberikan beberapa hiburan yang diselipkan adegan jenaka. film ini menegaskan bagaimana cara menjaga ukhuwah yang baik dengan keadaan saling cinta yang membuahkan keihklasan

Proses pembuatan film Cinta dalam Ukbuwah sama seperti halnya film yang lainnya berdasarkan hasil wawancara pada tanggal pada 23 Oktober 2017 bersama penulis skenario dan beberapa crew dan talent dari FMM. Pembuatan film CDU di awali dengan dengan brainstroming setelah ide cerita lalu melakukan diskusi bersama seluruh crew. Awalnya ide cerita cinta dalam semua dilatarbelakangi dengan fenomena sehari-hari banyak orang muslim yang bisa bertoleransi terhadap orang yang beda agama namun lupa cara bertoleransi dengan yang seagama hanya karena berbeda pendapat. Muhammad Ali Gifar menuturkan bahwa setelah melakukan diskuasi ia melanjutkan membuat skenario lalu crew yang lain bertugas menentukan talent. Talent FMM ini terkadang diisi oleh crew FMM atau membuka casting tergantung bagaimana kebutuhannya. Film CDU menggunakan talent yang non hijab yaitu kak Sita Aci sebagai Najwa penulis menuturkan:

“Bukan maksud kita buat ngumbar aurat ko' tapi kita hanya coba mengambarkan bagimana keadaan masyarakat yang sebenarnya bahwa ada orang berhijab ada yang tidak relevan aja sih. Jadi kalo disimpulkan bgaiaman FMM memilih talent ya"

Teknis produksi penulis saligus crew dari film Cinta dalam Ukhuwah inipun merasa bahwa yang di lakukan di FMM ini cukup melelahkan, karena beberapa adegan yang bersentuhan antara lawan jenis yang buka mahromnya kami selalu cut dulu. Perempuan dan laki-laki yang senderan kami ganti dulu bahunya. Lalu adegan yang ngelus kening kami ganti juga. Sampai sejauh ini kami masih coba jaga batasannya meski kadang orang masih saja bilang ini film Islam ko ada adegan mesra kan bukan mahromnya padahal memang asli suami istri. selebihnya ketika produksi kami selalu mengusahakan istirahat setiap waktu sholat dan tentunya sholat berjamaah. Secara langsung penulis skenario dan crew FMM tidak 
ingin film yang diproduksinya itu di sebut film dakwah tapi secara teknis dan produksinya film maker muslim bisa diketahui mengandung beberapa unsur dakwah.

\section{Bangunan Wacana Teks Film Cinta dalam Ukhuwah}

Berdasarkan proses dari hasil analisi yang telah di uraikan pada bab sebelumnya maka dapat di simpulkan bahwa "Film Cinta dalam Ukhuwah" merupakan film yang mengandung unsur dakwah dan berideologis Islam. Film Cinta dala Ukhuah diproduksi oleh Film Makker Muslim dengan kesadaran penuh untuk berdakwah. Respon yang di terima oleh para penggemarpun ikut memepngaruhi bgiman mereka konsisten berdakwah dengan entertain.film yang berdurasi 45 menit ini sangkat kental nilai ukhuwah dan nilai-nilai Islam, sehingga lebih jelasnya dapat di simpulkan bahwa Analisis Van Djik mengenai tekas terpaku pad 3 unsur yakni mikro struktur, super srtukur dan makro struktur. Setelah sianalisis lebih dalam ini adalah keismpulannya.

Pertama, Makrostruktur dari teks skenario pada film CDU ini yaitu topik besar sebagai garismerah adalah tema tentang Toleransi : Sesuai dengan tujuan dibuatnya film ini FMM ingin menegaskan bahwa terkadang kita lupa bagaimana cara bersikap Santun terhadap orang yang berbeda pendapat dalam agama Islam. Jangan sampai justru umat Islam jauh lebih Santun terhadap orang yang berbeda agama seperti dialog yang ditegaskan oleh Rio. Baru terjadi kalau keduanya punya niat bertoleransi keduanya punya sikap mau mengalah.

Dalam film Cinta dalam buah tema toleransi adalah poin paling kental pada awal opening sudah di gambarkan dengan adegan a ario, azzam dan sakti mereka nyantri dipesantren yang sama tapi fikih mereka berbeda. Digambarkan jelas ketika adegan alam yang berusaha menempelkan ujung kakinya ketika solat berjamaah kepada sakti sementara sakti terus menggeser shafnya karena merasa risih.

Ukhuwah dalam film ini konseptual dalam Islam sangat begitu kental terlihat pada setting. Azzam Rio dan sakti bersahabat sejak jaman Santri sampai kuliah meski mereka meski mereka mempunyai soal Fiqih. Alur cerita pun ditegaskan pada antiklimaks di mana akhirnya Najwa bisa diterima disamaratakan haknya dan sikapnya. Rio dan Azzam bisa saling merelakan dengan tujuan Ukuwah.

Inklusivisme penulis skenario menegaskan bahwa sikap inklusivisme pada film ini di gambarkan sikap mampu menempatkan diri sendiri 
sebagai bagian dari orang lain dari pemikiran, kelompok yang berbeda. Dengan kata lain ada sikap tidak merasa diri sendiri atau golongan lebih utama. Sikap itu tergambar pada tokoh Aryo yang menyikapi perbedaan dengan santai dan lebih relevan untuk tidak merusak ukhuwah yang sudah terjalin baik. Terlihat dari argumen dialog yang sederhana pada setiap adegan.

Superstruktur Super struktur adalah kerangka suatu teks tentang bagaimana struktur kamilat bisa terbentuk seperti apa yang di perlihatkan. Skematik merupakan startegi komuniakasi untuk mendukung makna umum dengan memberikan sejumlah alasan pendukung. Apakah informasi di berika di awal atau di akhir terganung pada makna yang didistribusikan dalam wacana.

Setiap teks pasti memeilki skema baik itu berupa laporan, berita, pidato percakapan. Bentuk teks lainnya seperti skenario atau naskah filmpun mempunyai aturan umum (outline). Jadi, maksud dari skema disini adalah aturan baku bagaimana suatu teks di susun dari awal sampe akhir. Dalam aturan baku ini ada kategori "yang wajib" ada dalam teks sebagai konveksi standar tetapi ada juuga yang tidak (Erianto, 2000:25)

Dalam sebuah cerita film, film memiliki kerangka untuk merangkai dan menyususn sebuah cerita. Dalam sinematografi, struktur cerita film lebih mempermudah penonton untuk mengikuti dan memahami cerita sebuah film yang ditayangkan. Adapun struktur cerita dalam film supratono, (1993: 15) sebagai berikut: Adegan pembuka (opening scene) Kesinambungan (contiunity), Pemunculan tokoh, Perkembangan alur/plot, Anti klimaks dan Ending

Microstruktur Struktur mikro adalah makna wacana yang diamati dengan menganalisis kata, kalimat, proposisi, anak kalimat, parafrase yang di pakai (Alex Shobur, 2011:72-73). Struktur mikro merupakan langkah terakhir dalam teori Van Djik bagian ini yang menjelaskan bagaimana struktur maka semua teks. Semantik dalam skema Vandjik dikategorikan makna lokal, yaitu makna yang muncul dari hubungan antar kalimat, hubungan antar antara profesi yang membangun makna tertentu dalam satu bangunan teks. Yang terpenting dalam hubungan antara filam masyarakat selalu dipahami secara lainnya kritik yang muncul terhadap perspektif ini didasarkan pada argumen bahwa film adalah Potret masyarakat di mana film itu dibuat. Struktur mikro ini trdiri atas pesan yang ditekankan terhadap 4 jenis unsur: 
Pertama, Semantik adalahMakna yang ingin di tekankan dalam film, makna dalam film CDU ini adalah tentang perbedaan. Perbedaan pendapat, perbedaan keadaan, perbedan kebiasaan, dengan latar dan seting yang sangan kontras sperti halnya di lembaga dakwah ada anggota tak berhijab

Kedua, Sintaksis merupakan startegi untuk menampilkan diri sendiri secara citra Dalam film CDU unsur dintaksis yang paling dominana film ini meceritakan banyak konflik secara kontinya sebagia strategi yang menjalsakna bagimnana pesan ini bisa saling berkesinabungan

Ketiga, Stilistik adalah cara yang di gunakan seorang pembicara atau penulis untuk meyatakan maksudnya dengan gaya bahasa dalam film ini campuran majas penegasan, hiperbolah dan eufimisme

Keempat, Retoris Suatu wacana seorang komunikastor tidak hanya menyampaikan pesan pokok, tapi juga kiasan dan unkapan metafora yang di pakai sebgai ornamen atau bumbu suatu teks. Cara Anita memberikan penjelasan kepada Kikin. Cara Kikin mengkspresikan marah. Cara cara Najwa bebas berpendapat. Cara mbak warung yang menyampaikan pedapat dan sanggahan. Kekahasan dalam dialog menjadi

\section{Kognisi Sosial Film Cinta dalam Ukhuwah}

Pada level kognisi sosial dipelajari proses produksi teks berita yang melibatkan kognisi individu penulis wartawan (Erianto). Berdasarkan hasil wawacara bersama penulis skenario maka hasilnya dapat di ketahui bahwa hasil teks atau naskah di pengaruhi oleh pengalama penulis skenarrio dalam tutrannya pda 27 oktober 2017:

Jadi, dasarnya kaya gini banyak orang yang bilang indonesia sedang menjelang masa kebangkitan Islam. Alasannya karena melihat banyaknya mesjid-mesjid penuh dan orang berlomba-lomba ikut kajian. Nah jadi menurut kami dan aku aku ist totality wrong,! Islam tidak bangkit hanya karena banyak mesjid mesjid mewah, Islam tidak bangkit karena mesjid penuh dan Islam tidak bangkit karena orang-orang pada kajian. Buat aku orang Islam itu bagus dan bangkit itu ketika mereka berkumpul untuk bersatu dan bermanfaat bagi yang lainnya. Terus apa hubungan sama CDU. Jadi gini ya kaum tradisionil sama kaum Islam yang modern mereka itu sedang perang dingin. Nah didepan orang-orang mereka bilang Islam itu rahmatan lil'alamin tapi kenyataannya sedikit saja perbedaan itu bisa jdi masalah buat mereka. 
Dari paparan di atas bisa di simpulkan bahwa pembuatan naskah seknario film CDU ini sangat di pengaruhi oleh pengalaman penulis. Perbedaan ikhtilaf dan furuiyyah dikalangan umat muslim yang mejadi kontras dan jelas. Inkslusivisme pun di angkat menjadi bahan yang di kontruksi bagaimana film ini mengankat unsur perbedaan dan toleransi. Serta menegaskna kita untuk tetap bersikap baik mengadapi perbedaan.
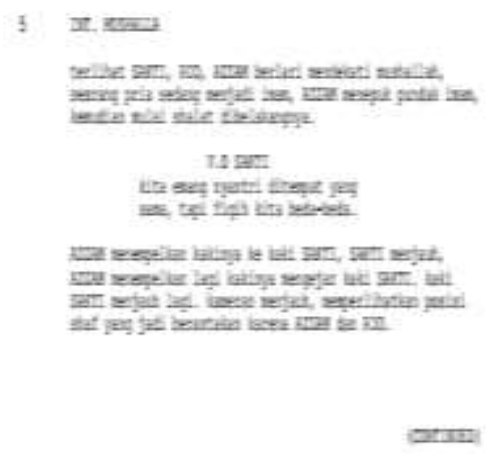

Sumber : Skenario Film CDU

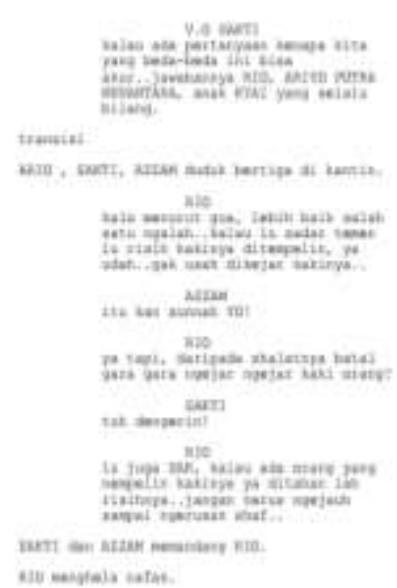

sill benytels safas.

Gambar 1 : Kutipan teks mengenai pesan yang di kontruksi dari wacana dalam skenario.

\section{Konteks Sosial menurut Wacana Film Cinta dalam Ukhuwah}

Pada level kognisi sosial dipelajari proses produksi teks berita yang melibatkan kognisi individu penulis wartawan (Erianto 70: 1994). Berdasarkan hasil wawacara bersama penulis skenario maka hasilnya dapat di ketahui bahwa hasil teks atau naskah di pengaruhi oleh pengalama penulis skenarrio dalam tutrannya pda 27 oktober 2017:

"Jadi, dasarnya kaya gini banyak orang yang bilang indonesia sedang menjelang masa kebangkitan Islam. Alasannya karena melihat banyaknya mesjid-mesjid penuh dan orang berlomba-lomba ikut kajian. Nah jadi menurut kami dan aku aku ist totality wrong,! Islam tidak bangkit hanya karena banyak mesjid mesjid mewah, Islam tidak bangkit karena mesjid penuh dan Islam tidak bangkit karena orang-orang pada kajian. Buat aku orang Islam itu bagus dan bangkit itu ketika mereka berkumpul untuk bersatu dan bermanfaat 
bagi yang lainnya. Terus apa hubungan sama CDU. Jadi gini ya kaum tradisionil sama kaum Islam yang modern mereka itu sedang perang dingin. Nah didepan orang-orang mereka bilang Islam itu rahmatan lil'alamin tapi kenyataannya sedikit saja perbedaan itu bisa jdi masalah buat mereka"

Dari paparan di atas bisa di simpulkan bahwa pembuatan naskah seknario film CDU ini sangat di pengaruhi oleh pengalaman penulis. Perbedaan ikhtilaf dan furuiyyah dikalangan umat muslim yang mejadi kontras dan jelas. Inkslusivisme pun di angkat menjadi bahan yang di kontruksi bagaimana film ini mengankat unsur perbedaan dan toleransi. Serta menegaskna kita untuk tetap bersikap baik mengadapi perbedaan.
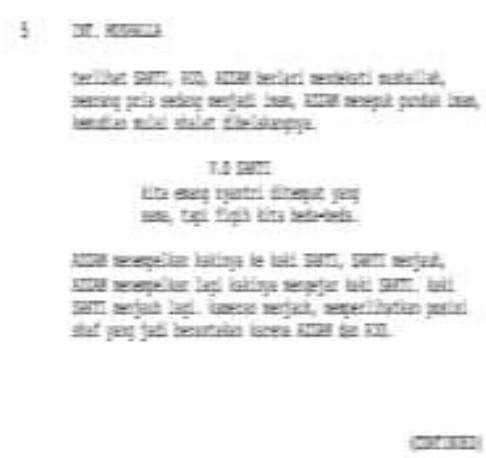

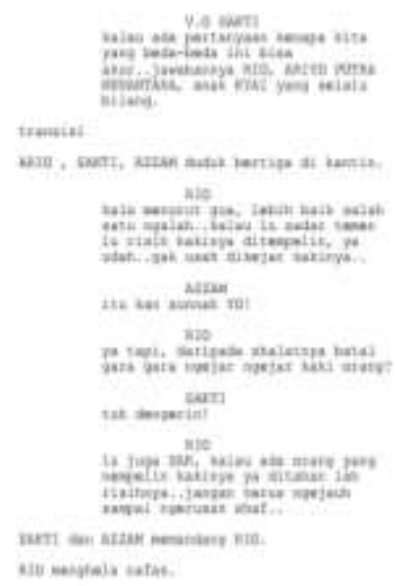

Gambar 1 : Kutipan teks mengenai pesan yang di kontruksi dari wacana dalam skenario.

\section{Konteks Sosial Film Cinta dalam Ukhuwah}

Aspek ketiga dari konsep analisis wacana Vandjik ini adalah bagaimana cara mempelajari bangunan wacana yang berkembang dalam masyarakat akan suatu masalah (Erianto). Perbedaan selalu menarik di perbincangkan banyak praktisis film yang sudah hebat membuat film. Banyak ustadz yang sering berceramaah dari panggung kepanggung dari mimbar ke mimbar, namun permasalahan umat Islam masih terus komplek berkembang. Seolah antara dakwah dan masyarakata menjadi ritual yang berjalan masing-masing. Maka, seperti apa yang di katakan Dedy Mizwar pada Talkshownya, bahwa setiap kegiatan itu harus mengadung 
humaniterest. Baik itu dakwah atau pun pembuatan film. Kritik sosial adalah salah satu tujuan fungsi dari suatu film dibuat.

Kepekaan sosial melalui pendekatan humanistik mejadikan cara satu metode yang baik dalam mecari data tidak hanya karya tulis ilmiah dan karya lainnya. Membuat naskan film memerluakan riset dan data untuk menggambarkan pesan agar mewakili realitas yang ada. Sehingga efek dari tujuan dakwah adalah adanya perubahan walapun tidak memaksa. Respon dari berbagai penonton di kolom komentar channel You tube bisa mewakili bagaimana respon masyarakat menyepakati hasil dari pesan yang berkembag dan di kontruksi menjadi klimaks dan anti klimaks yang tergambar. Berikut kutipan dari hasil wawacara :

"Waktu bikin CDU itu beberapa kali pengen nyindir, sampe beberapa kali di rombak dan aku berfikir klo di sindir dan di nyinyirin ahirnya ga berubah ya gimana? Jadi ya di bikin semanis mugkin sesederhana mungkin, makanya disini kita kemas dengan cara halus.
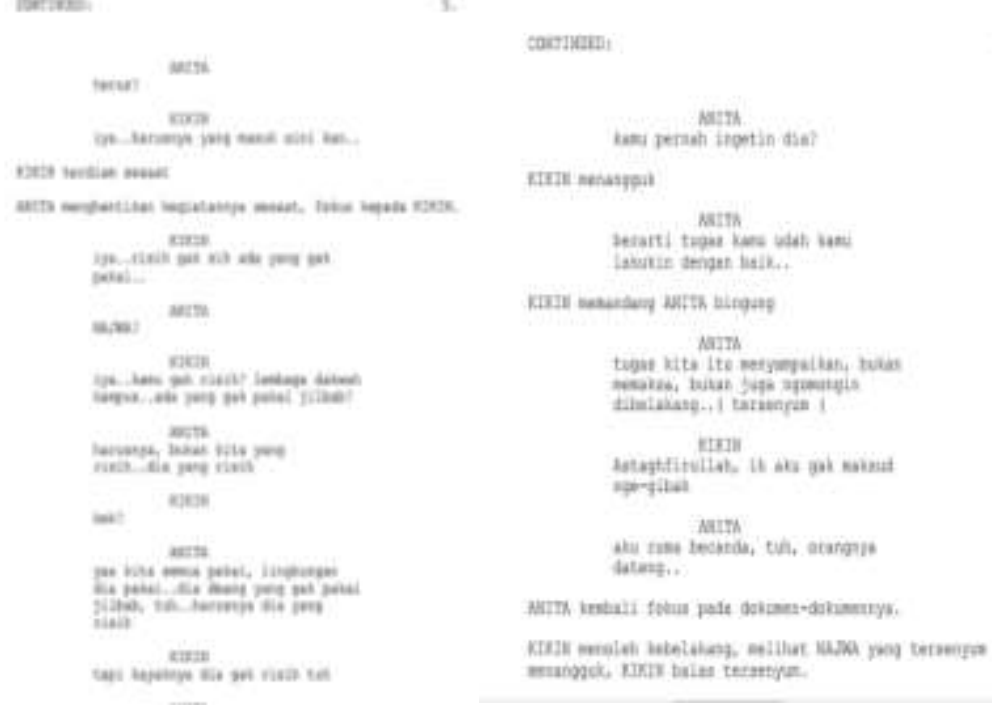

Gambar 2. Sikap penulis yang tergambar dalam dialog

Ada adegan di CDU yang maksa-maksa orang sama dengan dirinya, nah kita menampilkan hal yang lucu itu. Lalu yang kedua, CDU ini ada kepentingan politik contoh : si Azam bersikap kaya gti sama rio karena dia suka kepada Anita. Bohong kalau misalkan ada segolongan orang 
menyuarakan ke eksklusifannya, ada kalanya mengucapkan sesat ke orang lain karena adanya sesuatu yang berbeda.

Ditegaskan oleh penulis bahwa kontek sosial sangat mempengaruhi tuturnya:

"Karena kita percaya bahwa film bisa jadi control dan kritik sosial, propaganda yang baik, saya yakin dengan mereka menonton film kami, bisa merubah sikap mereka, walaupun mungkin ada yang nonton sampai 5 menit. Menjadi berubah yang lebih baik, why not? Ada yang bilang, emang ngaruh apa dakwah lewat film, paling nonton sampai 5 menit, ya bagus daripada tidak sama sekali. Jadi, dibilang tadi itu, ngaruh sih.. akhirnya kita bilang gini, setiap ada sosial trend yang terbaru, maunya sih kita bikin karya yang ada kaitannya. Kayak misalkan waktu masalah gay, apasih ?kita harus bersikap bagaimana sih buat berhadapan orang gay, apakah kita musuhin, apakah kita deketin tapi jaga jarak, apakah kita purapura gak kenal, FMM itu kayak menghadirkan itu sebenernya. Cuman belum ada kesempatannya aja. Banyak hal-hal yang kayak gitu yang belum dibahas sama FMM masalah-masalah di masyarakat banyak" semuanya sudah di list nantikan aja terus film-film kita di youtobe.

Jadi kondisi masyarakat itu memang menjadi stadar utama bagaimana ide cerita menjadi bisa di kembangkan. Khususnya untuk konsep kontruksivitas yang akan mengalir pada dialog-dialog dalam film. Di buktikan penulis skenario telah mengangkat film di Channel Youtubenya terbaru dengan issu Gay dalam kurun waktu sebulan setelah wawacara yang di lakukan.
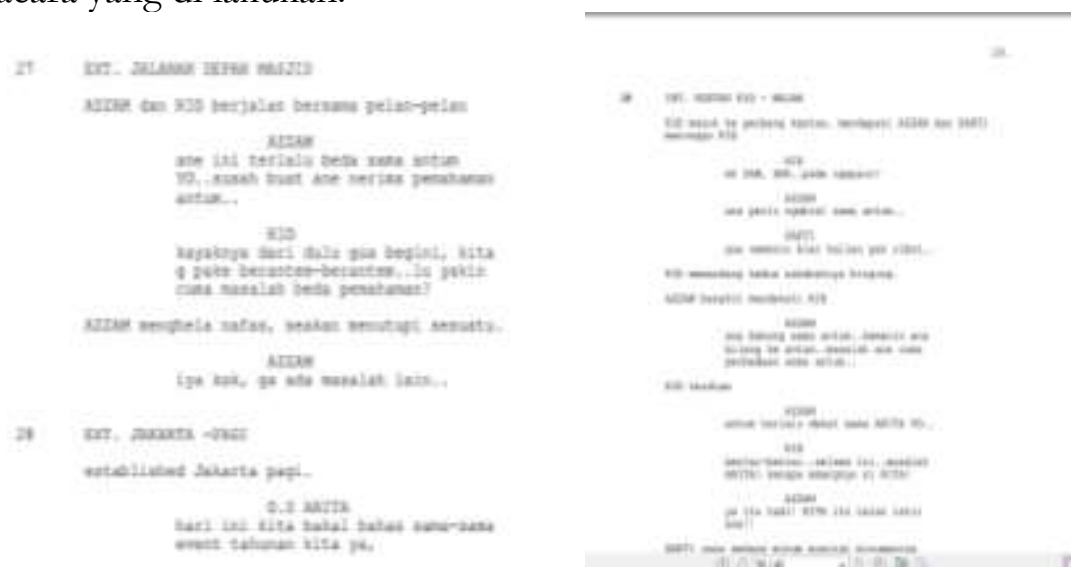
Y. F. Nursyamsi, D. Sholahudin, T. Sukayat

Gambar 3. Dialog yang berurut yang menegaskan anatar klimaks dan anti klimaks mengenai sikap terhadap wacana politik percintaan dan perbedaan madzhab yang di angkat.

\section{Subtansi Pesan Dakwah Film Cinta dalam Ukhuwah}

Subtansi menurut KBBI adalah watak yang sebenarnya dari suatu isi atau pokok. Telah dipaparkan bagaimana pesan yang terkandung dalam film secara umum. Beragam vidio banyak di produksi oleh Sineas Film. Namun pengemasan yang apik tanpa menyinggung banyak pihak adalah hal yang sulit. Subtansi film "Cinta dalam Ukbuwab" yang teranalisis adalah : Pertama, Tabayun. Tabayun dalam KBBI berarti pemahaman, penjelasan. Sebelum mengkritik sebaiknya di lakukan dulu atau makna lainnya perbedaan iktilaf antara dua pendapat. Film ini jelas memperlihatkan bagaimana tuduhan atau prasangkan dan berlaku seenaknya merupakan hal yang gegabah. Maka tabayun tergambar sebagai solusi untuk mengklarifikasi terhadap setiap persoalan ,yang baik seperti yang tergambar dalam firman Allah surat al Hujurat ayat 6: "Hai orang-orang yang beriman, jika datang kepadamu orang Fasik membawa suatu berita, Maka periksalah dengan teliti agar kamu tidak menimpakan suatu musibah kepada suatu kaum tanpa mengetahui keadaannya yang menyebabkan kamu menyesal atas perbuatanmu itu".

Ahanifiyyah as-sambah adalah sikap bertoleransi dalam Islam menurut Nurkhalik Ridwan (2002) pada buku kritik atas nalar di katakan bahwa sebaik-baiknya agama disiis Allah adalah al-hanafiyyah as-samhan ini adalaha semangat mencari kebenaran secara terbuka yang membawa pada sikap toleransi, terbuka, dan tidak sempit, tidak fanatik dan tidak membelengu jiwa. Apa yang di sebutkan dalam firman Allah pada surah yunus ayat 99: "Dan Jikalau Tubanmu menghendaki, tentulah beriman semua orang yang di muka bumi selurubnya. Maka Apakah kamu (bendak) memaksa manusia supaya mereka menjadi orang-orang yang beriman semuanya?"

Ketiga, Ukhuwah Islamiyyah adalah menjaga persaudaraan dalam Islam dalam segala hal seperti apa yang di lakukan oleh Ario kepada Anita dan Azzam kepada Ario, lalu Kikin kepada Najwa, mereka rela memperbaiki diri demi meperbaiki hubungan ukhuwah. d. Akhlaq adalah Cerdas dalalam menentukan sikap misalnya pada saat mengingatkan dengan cara yang baik dalam batasan yang di tentukan. Seperti halnya yang di gambarkan oleh Ario saat memergoki pak Bayu menyembunyikan 
tasnya ia justru melakukan gambaran bagaimana keburukan harus di balas dengan kebaikan. Ario justru minta maaf pada pada bapak dosen karena akhlak pada orang tua dan guru adalah yang harus di jaga. e. Qulan layyina Perkataan yang lemah lembut, Anita menegur Kikin saat Najwa bersikap tidak baik pada Najwa dengan cara yang baik dan lemah lembut. Ario pun mengajak berbicara dengan cara yang lembut saat jawa terpukul oleh ucapan kikin. f. Hikmah ialah mencintai segala kebijakan yang di berikan oleh Allah. Perkataan yang tegas dan benar yang dapat membedakan antara "Serulah (manusia) kepada jalan Tuhan-mu dengan hikmah dan pelajaran yang baik dan bantahlah mereka dengan cara yang baik. Sesungguhnya Tuhanmu Dialah yang lebih mengetahui tentang siapa yang tersesat dari jalan-Nya dan Dialah yang lebih mengetahui orang-orang yang mendapat petunjuk". Ikhlas adalah menerima segala sesuatu yang di berikan oleh allah dengan lapang dada. Artinya: jadilah Engkau Pema'af dan suruhlah orang mengerjakan yang ma'ruf, serta berpalinglah dari pada orang-orang yang bodoh.

\section{Wacana yang di Angkat pada Film Cinta dalam Ukhuwah}

Menurut Vandijk sesuatu karangan disebut wacana apabila di dalammnya menganding tulisan yang berkembang adalah hal-halyang berfungsisebagai: Suatu pernyataan (assertion), Pertanyaan (Question) Tuduhan (accusation), Ancaman (treat), Percakapan (convertation).

Film Cinta dalam Ukhuwah ini mengangkat wacana mengenai Yahudi isu-isu terkait perkembangan yang sedang hangat di sekitar kita di jadikan penyataan yang di bawakan dnegan gaya komedi tapi menyentuh. Berikut adegannya terlukis dalam dialog dari scene 21-24

Suatu pernyataan (assertion): Aku denger ya, sekarang muslimah berhijab itu tergila-gila sama artis korea. sampai mau dipeluk-peluk. ya Allah! Pertanyaan (Question): Ummat Rasulullah kan memiliki rasa malu, ini kok calon ibu pada gaklagi punya malu?. Itu game yahudi ya? Tau gak bbm naik kenpa?.

Tuduhan (accusation): Pasti gara-gara wahyudi (pelesetan dari kata yahudi). Ancaman (treat). Yahudi.

Percakapan (convertation): Percakapan continuity dari scene 21-24.

Setelah itu unsur dari kelima hal tersebut dikonstruksikan dengan dua hal yaitu: konstruksionis yang menekankan pada politik pemaknaan dan konstruksionis yang memandang kegiatan komunikasi yang terus dinamis. Jadi pada dpercakapan di bawah terlihat bahwa politik 
penekanan makna yahudi adalah pesan moral yang di tujukan kepada umat muslim untuk lebih cerdas dalam menyikapinya. Tergambar hasil konstruknya di scene ke 24 .

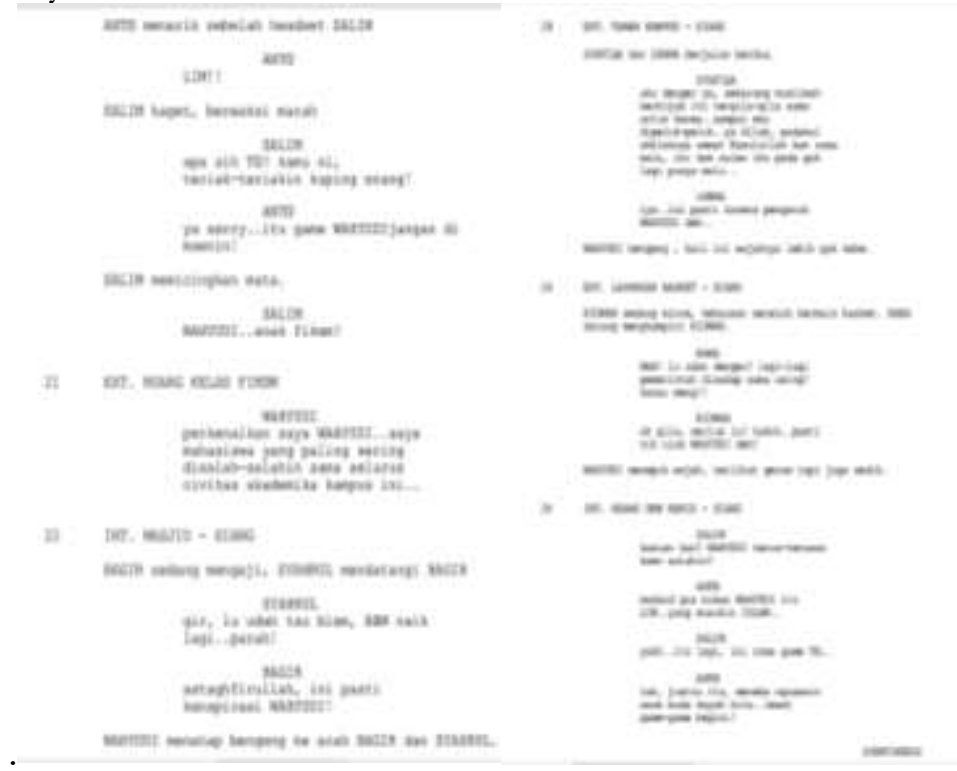

Sumber: Skenario Film CDU

Gambar 4. Pernyataan dan Konflik wacana "Stategi Yahudi"

\section{PENUTUP}

Berdasarkan proses dari hasil analisis yang telah di uraikan pada bab sebelumnya maka dapat di simpulkan bahwa "Film Cinta dalam Ukhuwab" merupakan film yang mengandung unsur dakwah dan berideologis Islam. Respon yang di terima oleh para penggemarpun ikut memepngaruhi bgiman mereka konsisten berdakwah dengan entertain. Dapat di simpulkan bahwa: a. Bangunan wacana teks film Cinta dalam Ukhuwah Analisis vandjik mengenai tekas terpaku pad 3 unsur yakni mikro struktur, super srtukur dan makro struktur. Setelah sianalisis lebih dalam ini adalah keismpulannya. Makrostruktur dari teks skenario pada film CDU ini yaitu topik besar sebagai garismerah adalah tema tenntang toleransi. Ukhuwah dan inklusivisme. Sedangkan suoperstruktur pada film CDU adalah Adegan pembuka (opening scene) Kesinambungan (contiunity), Pemunculan tokoh, Perkembangan alur/plot, Anti klimaks 
dan Ending. Microstruktur adalah pesan yang ditekankan terhadap 4 jenis unsur: Semantik Makna yang ingin di tekankan dalam film ini adalah tentanng perbedaan. Sintaksis merupakan startegi untuk menampilkan diri sendiri secara citra Dalam film CDU unsur dintaksis yang paling dominana film ini meceritakan banyak konflik secara kontinya sebagia strategi yang menjalsakna bagimnana pesan ini bisa saling berkesinabungan Stilistik adalah cara yang di gunakan seorang pembicara atau penulis untuk meyatakan maksudnya dengan gaya bahasa dalam film ini campuran majas penegasan, hiperbolah dan eufimisme Retoris .Suatu wacana seorang komunikastor tidak hanya menyampaikan pesan pokok, tapi juga kiasan dan unkapan metafora yang di pakai sebgai ornamen atau bumbu suatu teks

Kognisi sosial yang melatarbelakangi penulis skenario dalam membuat naskah film Cinta dalam Ukhuwah. Dari paparan bab sebelumnya bisa di simpulkan bahwa pembuatan naskah seknario film CDU ini sangat di pengaruhi oleh pengalaman penulis. Perbedaan ikhtilaf dan furuiyyah di kalangan umat muslim yang mejadi kontras dan jelas. Inkslusivisme pun di angkat menjadi bahan yang di kontruksi bagaimana film ini mengankat unsur perbedaan dan toleransi. Serta menegaskna kita untuk tetap bersikap baik mengadapi perbedaan.

Konteks sosial menurut wacana yang berkembang. Jadi kondisi masyarakat itu memang menjadi stadar utama bagaiman ide cerita menjadi bisa di kembangkan dari kepekaan soaial. Membuat naskan film memerluakn riset dan data untuk menggambarkan pesan agar mewakili realitas yang ada. Sehingga efek dari tujuan dakwah adalah adanya perubahan walapun sifatnya tidak memaksa. Respon dari berbagai penonton di kolom komentar channel you tube bisa mewakilin bagaiman respon masyarakat menyepakati hasil dari pesan yang berkembag dan di kontruksi menjadi klimaks dan anti klimaks yang tergambar.

Dalam kosidi idealisme yang sangat terpuruk sangat sulit memikirkan kualitas film, apalagi bicara film Islami. Namun bukan berarti kita harus pesismis dengan keadaan ini. Karena orang-orang akan jenuh menontot film yang memiliki kesamaan tema dan akan datang masanya mereka melikih tayanga yang lebih bermutu. Pernyataan tersebut di buktikan dengan merebaknya film yang bernuansa Islami.salah satunya adalah film karya film maker muslim yaitu Cinta dalam Ukhuah adalah film yang segmented yaitu hanya untuk kalngan tertentu oleh karena itu sebaiknya para sineas Islami lebih mmepertimbangkan hal-hal tersebut 
diatas agar dakwah melalui film dapat di terima dan di sukai oleh berbagi kalangan. Selain itu dalam membuat film dakwah sebaiknya tema yang di angkat lebih di vasriasikan lagi agar tidak terkesan monoton.

\section{DAFTAR PUSTAKA}

Anshsory, I. (1995) Mujahid Dakwah. Bandung: CV. Diponogoro.

Dulwahab, E. (2014). Dakwah di Era Konvergensi Media. Ilmu Dakwah: Academic Journal For Homiletic Studies, 5(16), 19-34.

Efendi, H. (2008) Industri Perfileman Indonesia. Jakarta: Erlangga.

Efendi, O. (1988). Ilmu Komuniasi Teori dan Praktek. Bandung: Remaja Karya.

Erianto. (2009). Analisis Wacana Kritis Media Teks. Jakarta

Kusnawan, A. (2004). Komunikasi dan Penyiaran Islam. Bandung: Benang Merah Press.

Oetomo, D. (1993). Kelabiran dan Perkembangan Analisa Wacana. Yogyakarta: Kanisius.

Rani, A. (2004). Analisis Wacana Sebuah Kajian. Malang: Bayu Media.

Sadiah, D. (2015). Metode Penelitian Dakwah. Bandung: Remaja Rosdakarya.

Saputra, I. (2013). Pergulatan demokrasi Jurnalisme dan Infotaimen dalam Industri Televisi. Jakarta: Gramedia.

Sobur, A. (2001). Analisis Teks Media Suatu Pengantar Untuk Analisis Wacana, Analisis Semiotik dan Analisis Framing. Bandung: PT. Remaja Rosdakarya 